\title{
Analyzing Economic Impacts of Electromagnetic Contamination Emitted from Communication Towers and Cell-Phone - A Case Study
}

\author{
Lorance Yahya Salih
}

College of Economic and Administration, University of Baghdad, Baghdad, Iraq

\begin{abstract}
The environmental problem can be attributed to a number of causes which affect the economic ideology. The economic theory deals with the environmental assets, such as water, air and soil, besides many other natural resources which exist on and inside the Earth, as free goods that are "up for grabs" to whomever and in whatever way without limits and free of charge. This is the core problem of environment and resources. A study on the cell-phone transmission stations concludes that relevant operators transmit at frequency ranges beyond the international standards and that the highest density of capacity transmitted is $24,7119 \mathrm{~m} / \mathrm{mw}$, a result which proved through testing and analysis maintained in the study area to have negative impacts on human health. 32\% of the study participants confirmed that conclusion. Also, by estimating the economic burdens resulting from this type of environmental deterioration it is found not cost-effective, as the direct costs within the study area is approximately 1666897 USD. As a result of the market failure to estimate and internalize these costs, i.e. negative external impacts, into the service production costs, a third party, the state for example, is needed to step in and have the costs of such effects internalized through imposing taxes and charges.
\end{abstract}

Keywords: Radioactive contamination, Electromagnetic radiation, Negative externalities, Economic costs

\section{Framework and Review}

\subsection{Introduction}

The world today undergoes a massive revolution in information and communication technology accompanied with a rapid expansion in utilizing technological systems, which are emitting electromagnetic radiation, such as radio and television transmission stations, radars, satellite broadcasting, industrial, medical and household appliances, including microwave ovens, and finally mobile phones. Using of these devices has become inevitable and unavoidable for billions of people, although the number of warning calls and those fairly reassuring over the consequences of carrying and addicting to cell-phones have largely increased. With the high level of exposure to such waves, it is crucial to have more focus on the negative impacts resulting from them and to develop controls preventing people from potential harms. Technology is not an absolute virtue, it could have some concomitant drawbacks when miss- or overused. The cell-phones concept is based on the transmission of information to a nearest transmitter and receiver station, which is typically installed on building roofs or on top of towers in residential areas. Such stations are interconnected through land network and then with a satellite. Despite the concerns raised by scientists over the harms of cellular phones, most advanced countries that introduced this technology have conducted over the last 20 years a lot of researches on the potential harmful effects from the exposure to electromagnetic waves, concluding that these waves have zero effect as long as they are in line with the standards set by the international organizations and institutions. (Hayawi 2005)

In recent years, researchers have had accumulated experience especially after the widespread use of mobile phones and exposure of people to the waves emitted from communication towers, which are increasingly proliferating to meet customer needs. Exploring and Reducing risk levels have become the focus of researches by those scholars as this type of studies helps identifying the nature of hazards might these fields impose when exist.

1.2 Accordingly, this paper relies on the following hypothesis

"Increased radiations emitted from cellular phone transmission towers imply high economic and social costs that could hamper the progress of growth and development in many countries. There are several means to regulate, control and reduce wave emissions, among which experiences of other countries in this regard"

\subsection{The purpose of the study is based on the following}

1) Studying exposure level of electromagnetic waves emitted from mobile phone transmitters.

2) Identify whether the results obtained conform with international standards.

3) Compare the results obtained with EFC_400C frequency simulation software, and draw mathematical relation between the practical side results and simulation software results.

4) Estimate the economic cost incurred from radiation effect.

\subsection{Methodology}

To prove this hypothesis, the research paper employs analytical and descriptive framework building on the references, studies and new publications concerned with the environmental aspect, contamination, and estimated environmental deterioration costs. The paper was based on 4 sections. Section (i) covers the introduction, paper 


\section{International Journal of Science and Research (IJSR) \\ ISSN (Online): 2319-7064}

Index Copernicus Value (2015): 78.96 | Impact Factor (2015): 6.391

methodology, and referential overview of some studies relating to the negative economic impacts of electromagnetic waves. Section (ii) discusses the international standards for allowable emission levels of radiation and analysis the economic effects from emission with estimate economic cost. Section (iii) deal with the practical side of the towertransmitted density values results, cell-phone masts, in the study area. Finally, section (iv) includes recommendations and conclusions.

\subsection{Description of the study area.}

This paper investigates one tower of Asia cell, an Iraqregistered Telecommunication Provider, located in Tikrit University, which is cantered at ( $\mathrm{y}, 43.657241$ and $\mathrm{x}$, 34.679202) axes and operated within range GSM900 and GSM1800 as a small base station. EFC400TC software was applied to find out whether the practical side results identifies with the results of theoretical side, and usability of the software applications to do additional surveys and investigations.

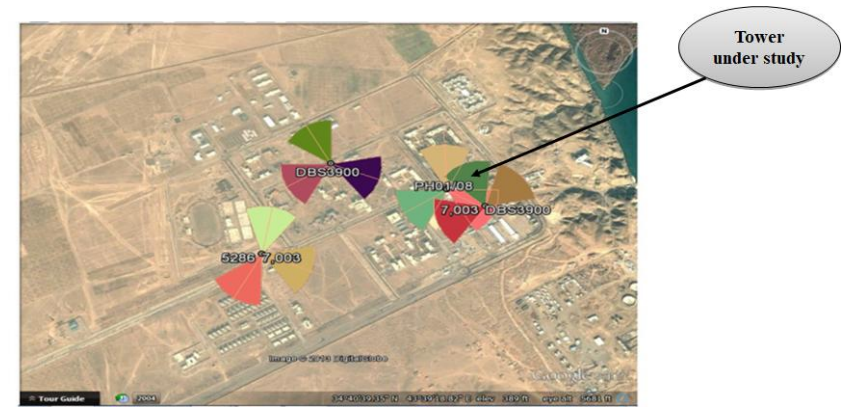

Figure 1: Illustrates aerial image of the study area

\subsection{Literature Review}

With the increased number of mobile phones call volume, erection of mobile networks and towers became a must. Thus, new towers had to be erected in many places. At the same time, however, that begged the question about the hazards of electromagnetic fields of these towers and cellphones to health, especially for large groups of people who feel still unclear about this issue. As a result, scientist urged by the impelling need to provide sufficient information in this regard embarked on studying such effects on the public health and finding out safe living distances. (Kundi and Hutter, 2009) studied cellular phone effects on human health and noted that they were unpromising by WHO. The study, also, showed varying results for the exposure to transmitters and weak evidence of GSM. Conducting two environmental studies on cancer risk from two adjacent transmitters, the scholars found that there is more danger at a radius of 350$400 \mathrm{~m}$, which cannot be at the same location.

Another study in the University of Mosul by (Al Lohaybi, 2010) showed that the power density transmitted from cellphones stations in the study area was beyond (Salzburg, 2002) standard, and that the results obtained were approximate to the results of simulation software at the same points.

(Mausa, 2011) studied in Nablus, Palestine the level of exposure to transmission stations, measured frequencies from several stations and compared them with FCC\&ICIRP standards to find if they live up to the standard or not in order to put answers to the public questions and concerns. The results proved that the frequencies were in compliance with the international standards ranging from $200 \mathrm{KHz}$ to $3 \mathrm{GHz}$.

In a study by (Kauri an Dhami,2012), they noted that radio wave radiations emitted from cellular phone towers represent new type of pollution. Also, they defined the highest and lowest field exposed to radiation around the transmitter, and found that the power density varies inversely with distance and the value of power density atop the tower was at $40 \mathrm{~m}$ height in most of the transmission directions.

(Repacholi, 2012) researched the impact of low frequencies and confirmed potential cancer risks to human beings as a result of exposure to magnetic fields with low frequency range of $50-60 \mathrm{~Hz}$. Based on the total analyses of previous literature on epidemic diseases, the study asserted the relationship between exposing to low frequency magnetic fields and cases of cancer in children.

(Sivani, 2012) study on the impact of electromagnetic frequencies generated within the human environment from transmitter towers was built on previous years reports. The conclusions argued that electromagnetic waves could modify neurotransmitters function and brain blood carriers, as well as human electrophysiological characteristics, cellular metabolism, calcium, genes and proteins density even at low transmission fields.

A study on rats conducted by (Poulletierde Gannes et al.; 2013), in which a $2.14 \mathrm{GHz}$ signal was applied for 20 days during pregnancy period, demonstrating no negative side effects on the pregnancy or embryo development. However, it failed to justify the anomalies in the rat's attitude, resulted from frequent exposure to EMF radiations. (Kostof and Lan, 2013) conducted a study on the electromagnetic radiation fields and argued that they have single or compound effects on the biological system. They found that these fields imply negative or positive impacts. The positive ones are noted in treating chronic diseases such as cancer, through improved ionizing of radiation and accelerated recovery of wounds and injuries, whereas the negative effects included carcinogenesis and genetic modification of cells.

\section{Conceptual Framework and Economic Analysis of the Associated Effects}

\subsection{Preface}

Assessing environmental effects is one of the issues concerned with the effects of various development activities. Analysis or assessment of economic environmental effects is considered an element of development planning due to the fact that economic growth costs are now higher than benefits. Among these costs, environment pollution and resources waste...etc. Thus, the industrial countries have been adopting and recommend developing states to adopt the assessment process of environmental impacts in development projects

\section{Volume 6 Issue 7, July 2017 www.ijsr.net}




\section{International Journal of Science and Research (IJSR) \\ ISSN (Online): 2319-7064}

Index Copernicus Value (2015): 78.96 | Impact Factor (2015): 6.391

and warn them about the frequent problems and errors these states undergone. This line attracts now the attention of the countries and organizations worldwide, including the UNDP, WHO and other organizations and institutions.

\subsection{Formal Standard of the Exposure to Radiation from Communication Towers}

\section{1) ICNIRP standard}

The International Commission on Non-ionizing Radiation Protection considered the temperature rise of a body exposed to radiation as a base to set the maximum permissible exposure limits for electromagnetic transmission. Table 1.1 shows the reference levels of exposure limits according to the Commission guidance. (International Commission on NonIonizing Radiation Protection, 1988)

Table 1: maximum limits of exposure based on ICNIRP guidelines

\begin{tabular}{|c|c|c|c|}
\hline $\begin{array}{c}\text { Power density } \\
(\mathrm{W} / \mathrm{m} 2)\end{array}$ & $\begin{array}{c}\text { magnetic field } \\
(\mathrm{A} / \mathrm{m})\end{array}$ & $\begin{array}{c}\text { Electric } \\
\text { field }(\mathrm{V} / \mathrm{m})\end{array}$ & $\begin{array}{c}\text { Frequency } \\
(\mathrm{MHz})\end{array}$ \\
\hline & 100 & 5000 & $5 \times 10-5$ \\
\hline- & $0.23 \mathrm{f} \mathrm{1} / 2$ & 87 & 0.1 to 1 \\
\hline- & $0.23 \mathrm{f} 1 / 2$ & $87 / \mathrm{f} 1 / 2$ & 1 to 10 \\
\hline 2 & 0.073 & 27.5 & 10 to 400 \\
\hline $\mathrm{f} / 200$ & $37 \times 10-4 \mathrm{f} 1 / 2$ & $1.375 \mathrm{f} 1 / 2$ & 400 to 2000 \\
\hline 10 & 0.16 & 61 & 2000 to $3 \times 105$ \\
\hline
\end{tabular}

\section{2) Standard of the Federal Communications} Commission, FCC

FCC set limits similar to those of the ICNIRP, but it developed them to the extent that they cover wider range of frequencies not listed in the previous standard. Table 2 shows the limits for maximum permissible exposure according to FCC regulations. (Ronald 2001)

Table 2: maximum permissible limits of exposure based on FCC regulations

\begin{tabular}{|c|c|c|c|}
\hline $\begin{array}{c}\text { Power density } \\
(\mathrm{W} / \mathrm{m} 2)\end{array}$ & $\begin{array}{c}\text { magnetic } \\
\text { field }(\mathrm{A} / \mathrm{m})\end{array}$ & $\begin{array}{c}\text { Electric } \\
\text { field }(\mathrm{V} / \mathrm{m})\end{array}$ & $\begin{array}{c}\text { Frequency } \\
(\mathrm{MHz})\end{array}$ \\
\hline 1000 & 1.63 & 614 & 0.3 to 1.34 \\
\hline $1800 / \mathrm{f} 2$ & $2.19 / \mathrm{f}$ & $824 / \mathrm{f}$ & 1.34 to 30 \\
\hline 2 & 0.073 & 27.5 & 30 to 300 \\
\hline $\mathrm{f} / 150$ & - & - & 300 to 1500 \\
\hline 10 & - & - & 1500 to 105 \\
\hline
\end{tabular}

\section{3) Salzburg Standard}

With the dramatic increase of mobile phones users in recent years and proliferation of home appliances emitting electromagnetic radiations, new standards accommodating the current standing need to be developed. In 2000, Salzburg Standard was set. It was updated in 2002 to be more limiting than the previous standards. Table 3 includes the maximum permissible limits of the exposure standard. (Oberfeld and Koenig 2006)

Table 3: maximum permissible limits under Salzburg Standard

\begin{tabular}{|c|c|}
\hline Salzburg 2000 & $1 \mathrm{~m} \mathrm{~W} / \mathrm{m} 2$ \\
\hline Salzburg 2002 outdoor propagation & $10 \mu \mathrm{W} / \mathrm{m} 2$ \\
\hline Salzburg 2002 indoor propagation & $10 \mu \mathrm{W} / \mathrm{m} 2$ \\
\hline
\end{tabular}

\section{4) Iraqi Standard, 2010}

In 2010, the Ministry of Environment of Iraq issued instructions governing cellular phone towers. The instructions limited human exposure to the radiation from any component of a cellular phone to a level not exceeding 0.4 $\mathrm{mw} / \mathrm{cm} 2$. The standard provided that entry into high level energy zones on the front side of the transmission front shall not be allowed.

\subsection{Health effects of communication towers}

Major diseases and health risks targeting a human when being exposed to electromagnetic contaminants, which exceed permissible limits, as mentioned in the previous tables, include the following (Abdul Latif, 2, 2011)

1) General feeling of exhaustion, feeble, slackness, and no mood to work.

2) Brain function disorder

3) Embryo abnormalities

4) Development of some cancers, such as breast cancer and blood cancer, etc.

\subsection{Factors contributing to health effects of cell towers}

The hazardous effects of cell towers are caused by their radiations, and the way such radiations react with human cells. There are, at least, three critical confirmed relevant cases. (Abbas, 19, 2014)

1) Interference of radiation electric field in the human cells.

2) Interference of radiation magnetic field in the human cells.

3) Absorption of radiation energy by human body cells.

\subsection{Assessing Environmental Effects Concept.}

Assessing environmental effects refers to the study of potential positive and negative impacts of a project on the environment from natural, biological, economic and social perspectives. These impacts are assessed in terms of their social costs and benefits, as well as environmental effects as a criterion to select from the available alternatives (Hujazi, 2003). Based on this definition, we find that environmental assessment helps economic decision makers choose among different available alternatives, hence, serves as a means to determine which project is the best.

\subsection{E conomic Costs of Environmental Degradation}

Many experts are aware that continuous environmental degradation will eventually lead to heavy economic costs. The contamination manifestations from human activity, economic advancement and development endeavors, which finally turn into different human wastes shoulder the economy heavy burdens in response to such effects. Besides its impact on human health and natural resources, environmental issues imply many costs. Assessing such costs is very difficult, as these problems have multiple intangible elements. There are direct and indirect costs which can be divided according to a number of studies into several types.

1) Pollution-related health damages costs. These costs include medical and treatment costs of pollution diseases and could reach heavy amounts as s result of long-term

\section{Volume 6 Issue 7, July 2017}




\section{International Journal of Science and Research (IJSR) \\ ISSN (Online): 2319-7064}

Index Copernicus Value (2015): 78.96 | Impact Factor (2015): 6.391

health damages, especially for those ensued from the exposure to chemical and radiation contaminants.

2) Economic Costs of Low Productivity. Employees and individual low productivity and efficiency are caused by continuous exposure to pollution, specifically in factories environment, as well as by health deterioration in densely populated cities. Moreover, economic loss has greater costs than the productivity costs or output costs according to the traditional standards. The loss of a single working day due to health problems is considered an economic loss. Even diseases and ailments which have nothing to do with work loss, yet resulting from ageing and mortalities are seen as economic burden as well. (World Resources Institute and other, 1996)

3) Economic Costs relating to agricultural crop contamination, soil degradation, desertification, abuse of fish and animal resources and deforestation have negative impact represented in slower food growth and decreased touristic incomes as a result of pollution contamination effects on tourism areas. (Henna, 1991)

Other costs of contamination include deterioration of buildings, equipment and construction materials and declining property prices, as well as the cost of preventing and mitigating pollution-resulted damages, such as cost of control, treatment and remedy. Finally, there is the opportunity cost. (Ismail, 1986)

\subsection{Estimating Economic Costs of Contamination From Cell Towers and Mobile Phone Waves}

Communication companies provide services for the benefit of national economy. Yet these services should not be at the expense of citizens and their health safety or in return for bearing short-term and long-term economic burdens. Therefore, the developed countries establish specific standards for the radiation emitted from cellular tower, because the radio waves of the communication and mobile phone towers imply direct and indirect economic costs. The following chart shows these costs. (Researcher's design based on applicable sources). The previous figure shows that there are many damages, direct and indirect, and some of them can be defined while others cannot.

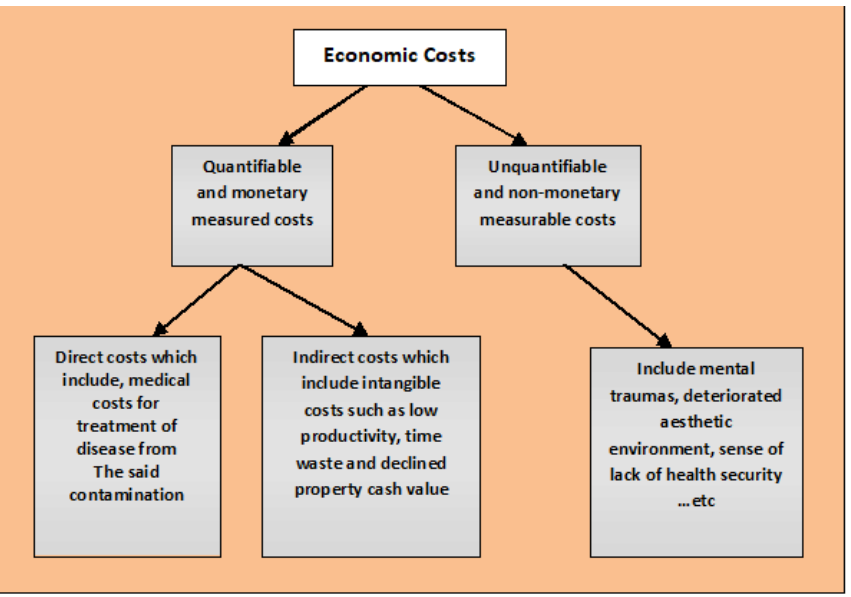

Chart 1: Classification of economic costs of mobile phone and cellular towers waves

\subsubsection{Estimating Quantifiable and Monetary Economic Costs}

\section{Direct economic costs}

Direct costs are incurred by the injured citizen from exposure to radiations. These include treatment and therapist costs. The survey conducted in the study area showed that $32 \%$ of those being vulnerable to radiation suffered from headaches, feeble, anxiety and bad temper. Based on the total number of study population, which was 22 thousand male and female students, it was inferred that

- The percentage of injured persons is $32 \% \times 22000=7040$ persons

- Following consultation with medical specialists in these diseases, it was found that the treatment cost per person ranges from 15000 IQD to 20000IQD, i.e. 17500 IQD on average.

- Accordingly, the therapist cost is (7040 injured persons $\times$ 17500 IQD therapist cost per person $)=123200000$ IQD

- In terms of treatment costs, the estimated cost per a person was 10000 IQD

Thus, the treatment cost is 7040 (persons) $\times 10000$ IQD $=$ 70400000 IQD

- The radiation exposure costs incurred by citizens will be in total:

- $123200000+70400000=193600000$ IQD, which is equivalent to $\$ 166897$ as the direct total cost.

- These costs are not final, yet evolving regularly, as long as the cause of the problem is out there i.e., they are cumulative costs over time.

\section{Indirect economic costs}

Indirect economic costs include time waste, absence from work, low productivity, declined property value and opportunity cost, as well as other intangible costs arising from wave effects emitted from cellular and mobile phones towers. Assessing this type of costs is very difficult, so we will discuss experiences of some countries in this field to take advantage of the results they obtained. In a report issued by the UNDP on the estimated economic losses incurred by some Asian cities as a result of traffic congestions, Bangkok suffers 272 million dollars losses a year for traffic congestions and Hong Kong annual losses totals to 293 million dollars. The report was issued in 1994 (UNDP, 1994). Today, we expect the problem to exacerbate due to the growing numbers of population in the developing countries. The estimations were made only pertaining to traffic congestion, while as for health deterioration and associated time waste and absence from work, there is no thorough and careful estimations on health problems in the developing countries, which make it difficult to have estimations of such costs.

\subsubsection{Unquantifiable and non-monetary costs}

These types of costs that an individual must incur are associated with the future effects on his/her health, degraded environmental condition, and lack of environment aesthetic value, which would gradually undermine the environment value. It is also uneasy to make assessment of such costs since their effects appear only after a while and consequently have future impacts on subsequent generation in terms of 


\section{International Journal of Science and Research (IJSR) \\ ISSN (Online): 2319-7064 \\ Index Copernicus Value (2015): 78.96 | Impact Factor (2015): 6.391}

natural resources and pristine environment.

\section{The Practical Side and Discussion of Results}

\subsection{Preface}

This section reviews the simulation results of power density emitted from the cellular tower in the study area, and the form and pattern of its distribution over distance by EFC_400TC software. It includes also the field measurements determined with the Spectrum HF Analyzer. The section presents the results of electromagnetic waves effects and whether they are applicable to the international standards.

\subsection{Simulation with EFC_400 TC}

A simulation of the tower centered at the mentioned axes was created based on the entry of relevant variables. The buildings nearby the study area were drawn depending on the axes of the buildings, which were determined through the aerial photography in the software. The simulation of the described tower included identifying the most affected areas and the power density gradient. Power density was calculated at selected points to understand to what extent the software results match the practical side results. Table 4 includes the axes of the points and the power density measured in the field. (The table is by the researcher effort based on the said software)

Table 4: axes of the points of measurements and field power

\begin{tabular}{|c|c|c|c|}
\hline $\begin{array}{l}\text { observation } \\
\text { points }\end{array}$ & $X$ axis & $\begin{array}{l}\text { density } \\
\text { Y axis }\end{array}$ & $\begin{array}{c}\text { Field measurement of } \\
\text { Power density }(\mathrm{mw} / \mathrm{m} 2)\end{array}$ \\
\hline 1 & 376987 & 3838319 & 0.21919 \\
\hline 2 & 376960 & 3838332 & 0.0045683 \\
\hline 3 & 376936 & 3838367 & 0.02096 \\
\hline 4 & 376908 & 3838397 & 0.07857 \\
\hline 5 & 376889 & 3838419 & 0.06948 \\
\hline 6 & 376854 & 3838470 & 0.01067 \\
\hline 7 & 376833 & 3838479 & 0.006179 \\
\hline
\end{tabular}

Figure 2 represents a 2D image of the study area taken from the application, which shows propagation of power density in coloured contours format. Figure 4 is a 3D image taken from the software for the study area shows the distribution of power density. (Figure 3, 2 is by the researcher effort based on the said software)

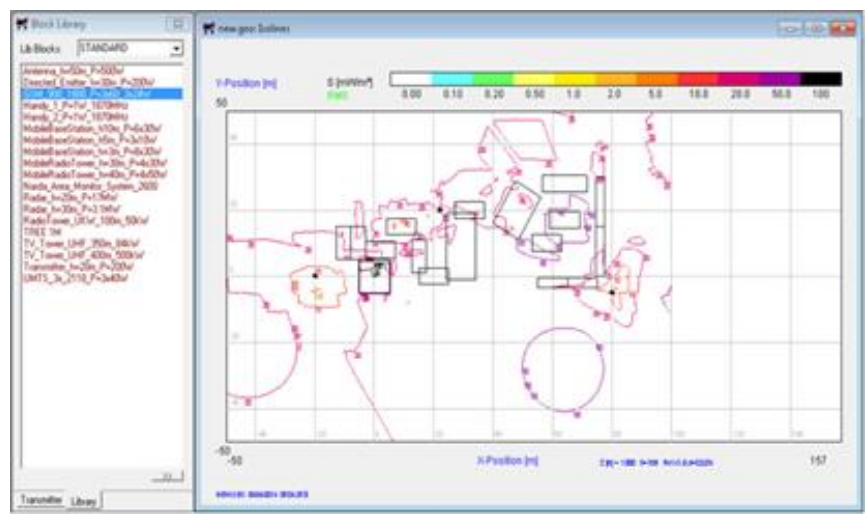

Figure 2: 2D image shows the distribution of power density

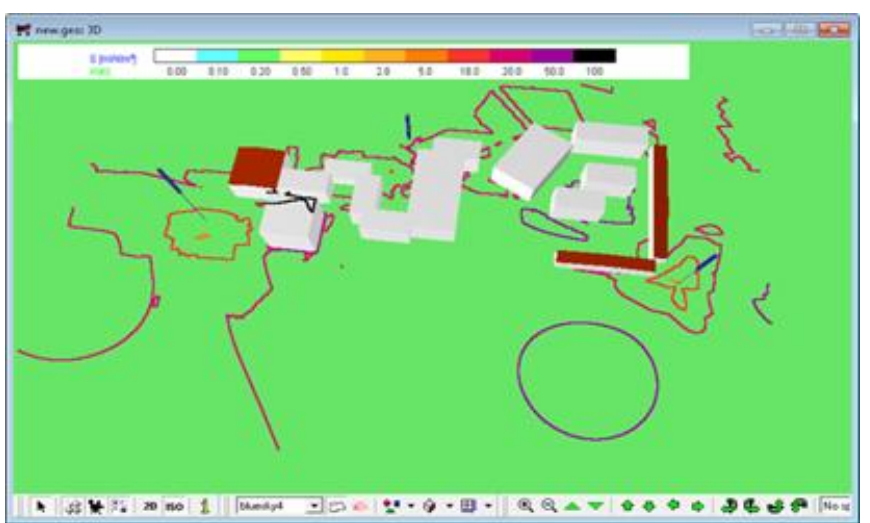

Figure 3: 3D image taken from the software for the study area shows the distribution of power density

Figure 4 shows the results measured through the simulation software at the points mentioned in table 4 and compare them with the international standards. (Researcher's preparation based on table 4)

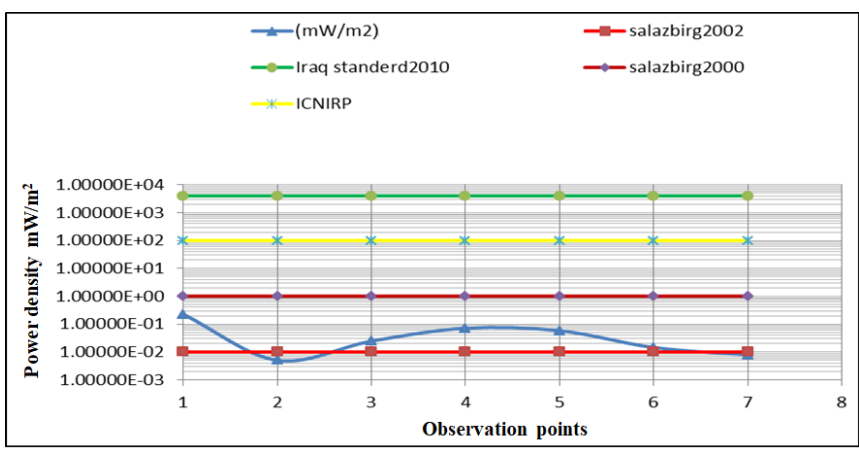

Figure 4: illustrates the results measured in the simulation software at the observation points and compares them the international standards

Figure 4 indicates that the results are inconsistent with Salzburg Standard, 2002. This agrees with AL Lohaybi, 2010 view of the same. The finding was acceptable since the fieldmeasured results and at the same selected points were also non-conformant with 2002 Salzburg standard. It should be noted that the simulation results obtained at selected points represent the accumulative totality of density emitted from the tower at such point.

\subsection{Results and analysis of the field measurements}

The results were obtained by the electromagnetic radiation detection meter of the said tower. The table shows that the cell tower transmits in different frequencies. The results were compared with the international standards and Iraqi standards of 2010, yet Salzburg's of 2002 was adopted.

3.3.1 The relationship between power density and distance from cellular tower towards the 1st impact point.

Figure 5 shows the field measurements of the tower towards the 1 st effect point of GSM900. Measurements within the observation points ranging from $15-30 \mathrm{~m}$ between one point and another were taken. Figure 3.4 indicates that the power density transmitted is oscillated, and all the values were consistent with the international standards as well as the Iraqi

\section{Volume 6 Issue 7, July 2017 www.ijsr.net}




\section{International Journal of Science and Research (IJSR) \\ ISSN (Online): 2319-7064}

Index Copernicus Value (2015): 78.96 | Impact Factor (2015): 6.391

standards for all the observation points, yet they were approximately in line with the standard of Salzburg, 2002. This agrees with AL Lohaybi, 2010 and Mausa, 2011 results, who argued that the power density sent out of low-frequency cell towers are in line with the international standards. Table 3.2 shows the axes of observation points and power density values at these points in relation to the tower of the student center towards the 1 st effect point.

Figure 6 clarifies the propagation of power density in terms of the frequency for GSM1800 of the same tower for the direction of the $1 \mathrm{st}$ effect point. It was noted that the propagation of power density for all points was within the Iraqi standard and ICNIRP standard, however, very close to Salzburg, 2002 standard. Most of the points was beyond Salzburg, 2002, which coincide with the results of most scholars who confirmed that the power density of high frequencies are not in line with the standards in some open points and that the fluctuating power density values can be attributed to the buildings and trees in the area, which block a great deal of the radiation energy. Open areas are more susceptible to the radiation effects than built-up areas. This agrees with (Hutter et al., 2006) results, who explored power density propagation of GSM transmission stations in rural and urban areas, concluding that power density in rural areas are higher than that in urban areas, which he ascribed the reason to the density of buildings and insufficient open spaces in urban areas. Figure 7 indicates pattern and distribution of power density as for GSM900 and GSM1800 frequencies for the same tower and in the direction of the 1st effect point and at the observation points in table 5 . We noted also that the power density for all the points were consistent with the Iraqi standard and ICNIRP standard, however, they were close to Salzburg, 2000 standard and beyond Salzburg, 2002 standard, which is logical on the practical side as figure 7 represents the algebraic sum of the abovementioned frequencies.

Table 5: shows the observation points axis and relevant power density values

\begin{tabular}{|c|c|c|c|c|}
\hline $\begin{array}{c}\text { Observation } \\
\text { points }\end{array}$ & X axis & Y axis & $\begin{array}{c}\text { power density } \\
900 \text { GSM }\end{array}$ & $\begin{array}{c}\text { power density } \\
\text { 1800 GSM }\end{array}$ \\
\hline 1 & 34.6792 & 43.6573 & 0.0000238 & 0.00653 \\
\hline 2 & 34.6794 & 43.6571 & 0.004010 & 0.02148 \\
\hline 3 & 34.6796 & 43.6568 & 0.0001363 & 0.004314 \\
\hline 4 & 34.6798 & 43.6567 & 0.0005175 & 0.12038 \\
\hline 5 & 34.6803 & 43.6562 & 0.012066 & 0.06459 \\
\hline 6 & 34.6806 & 43.6561 & 0.001378 & 0.06468 \\
\hline 7 & 34.6809 & 43.6559 & 0.0000297 & 0.008649 \\
\hline 8 & 34.6810 & 43.6558 & 0.0000311 & 0.003671 \\
\hline
\end{tabular}

*power density at $\mathrm{mW} / \mathrm{m}^{2}$

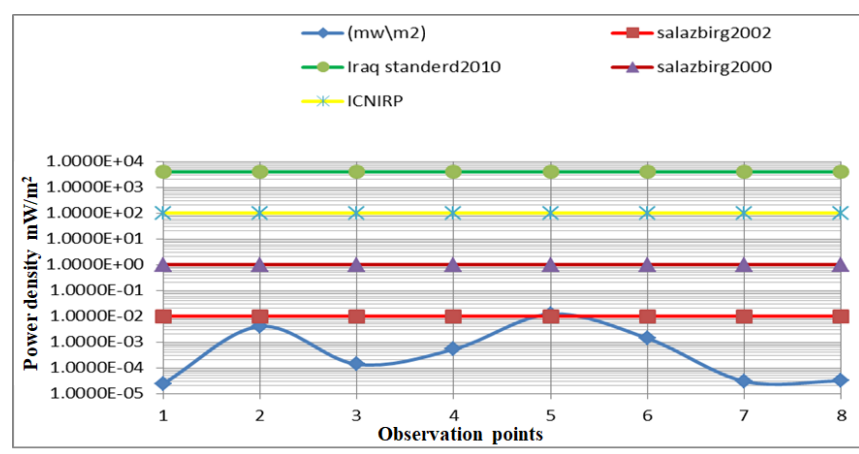

Figure 5: shows the field measurements of the tower towards the 1st impact point for GSM900

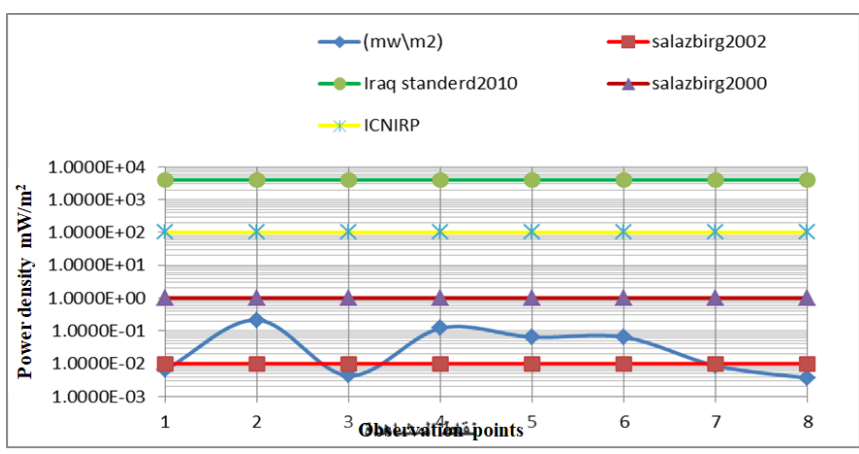

Figure 6: The propagation of power density for the tower towards the 1st effect point for GSM1800

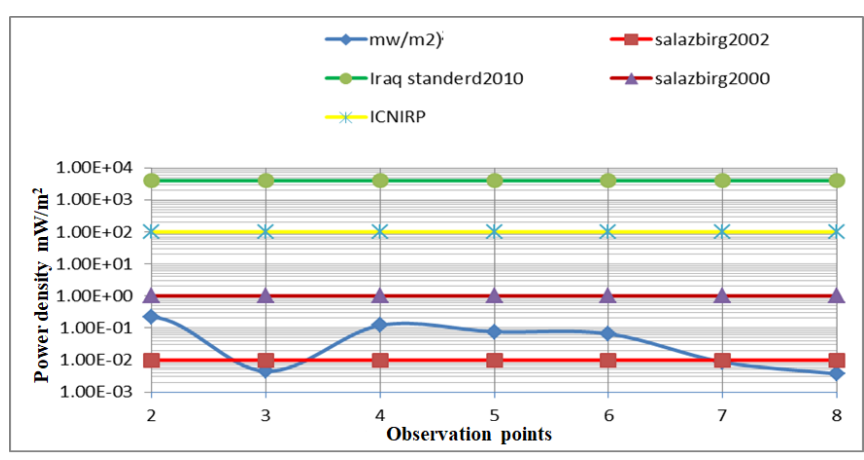

Figure 7: Algebraic sum of power density of the tower towards the 1st effect point for GSM900 and GSM1800

\subsubsection{Analysis and comparison of practical side results with simulation results}

Figure 8 illustrates the simulation results and their comparison with the results measured by the field electromagnetic waves measurement device at the same points.

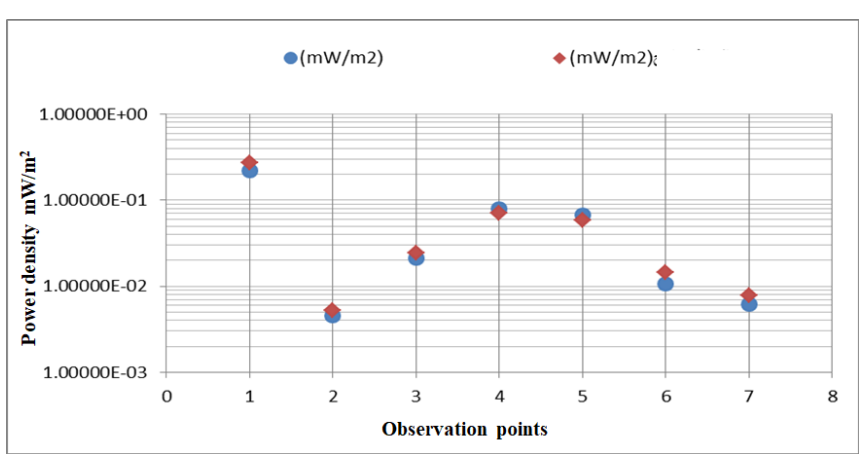

Figure 8: Illustration of the simulation results and practical side results

\section{Volume 6 Issue 7, July 2017 www.ijsr.net}




\section{International Journal of Science and Research (IJSR) \\ ISSN (Online): 2319-7064}

Index Copernicus Value (2015): 78.96 | Impact Factor (2015): 6.391

It was noted from figure 8 that the practical side results were approximate to those of the simulation software, which agrees with (AL Lohaybi, 2010), who explored the relation between the results and justified the cause of difference and lack of total identification by arguing that the wave measurement device simulates the nature in every detail and reports actual results, whereas the simulation software depends on the inputs relating to building characteristics, highets and construction area which cannot be fed into the software ideally to produce results that fully conform with the results of the practical side. Figure 9 shows the mathematic relationship between the field measured results and those measured in the software at the same points.

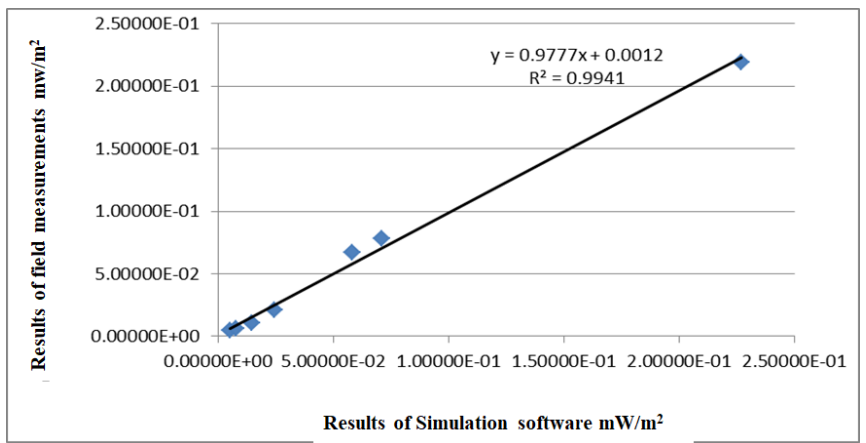

Figure 9: Illustration of the mathematic relationship between the field measured results and simulation results

Figure 9 illustrates the approximation of the results where the correlation coefficient is almost equal to 1 . The regression equation clarifies the mathematic relation between them.

$$
\mathrm{Y}=0.001+0.977 \mathrm{X}
$$

(Y) Is the field measured value.

(X) Is the software measured value.

Based on the linear regression equation and determination factor (R2), we infer that the equation explains to a large extent the relation between the field measurements $(y)$ and the simulation software measurements $(\mathrm{x})$, where the determination coefficient was 0.977. Thus, the model explains $97.7 \%$ of the above relation.

\section{Conclusions and Recommendations}

\subsection{Conclusions}

1) The highest power density value was obtained nearby the College of Pharmacy deanery, where it reached 24.7119 $\mathrm{mw} / \mathrm{m}$ at that point.

2) The more distancing from the transmitter footprint the less power density value. The safest point from the transmitter footprint is no less than $200 \mathrm{~m}$.

3) The waves of GSM1800 mobile phones have the highest power density value.

4) The EFC_400TC application, which produced approximate results to that of the practical side, can be applied.

5) The power density value, at the most open points where no impediments beyond Salzburg, 2002 standard, was in conformity with the international standards and Iraqi standard.
6) Iraqi citizens suffer heavy costs as a result of being exposed to electromagnetic waves, and these costs are accumulative and grow over time.

7) There are indirect economic costs, currently we are unable to assess, yet in the future they will impact the state economy.

\subsection{Recommendations}

1) Conducting studies on continuous basis in the denselypopulated residential areas to determine the power density level for all mobile phone systems and collect the accumulative values of these waves to understand their effects on people.

2) Measuring the power density of the electromagnetic waves emitted from the transmitters of internet services, as their frequencies are higher than those of the mobile phone system.

3) Reviewing and updating the Iraqi standard in line with the users' status with the prevalence of devices emitting electromagnetic waves.

4) Emerging of negative externalities. Since the market has failed to internalize the damages, a third party must take the initiative to impose taxes and charges and practice strict environmental control over communication companies to ensure their compliance with the specifications of transmission and towers height according to the national environmental updated standards.

5) Erecting cellular towers away from densely-populated areas to ensure the safety of dwellers.

\section{References}

[1] Abbas, Ahmed Zahid, 2014, "health damages of cellular towers, Republic of Iraq, Ministry of Human Rights, University of Mosul

[2] Abdul Latif, Mohammed Saad, 2011, "Electromagnetic Contamination and Safety Spaces", p2

[3] AL Lohaybi, Bariq.M.Abaoye,(2010), "The environmental electric and magnetic fields and their relationship with safety standards". M.Sc. University of Mosul, Iraq.

[4] Al-Hujazi, Abdul Kareem Hosny, 2003, "Global Environmental Concern”. A report on Iraq, p50

[5] Hanna, Amir Ahmed Ghazi, 1991, "Means of Environment Protection and Improvement/factory environment", Iraq's ministry of oil, Baghdad, p50

[6] Hayawi, Abdul Rahman Abdul Majeed, 2005, "Health Hazards of Mobile Phones", thesis, College of Engineering, University of Mosul

[7] Hutter, H.P.,H.Moshammer, P. Waller, and M.Kundi, (2006).,"Subjective, Sleeping Problems, and Cognitive Performance in Subjects Living Near Mobile Phone Base Station". Occupy. Environ. Med 63:307-313.

[8] Ismael, Tawfiq, 1986, "Current trends for industrialization and modernity and their effect on environment and alternative energy resources in ESCWA region", p263 
[9] Kostoff , Ronald N. Kosto and Clifford .G.Y.Lau, (2013). "Combined Biological and Health Effect of Electromagnetic Fields and other agents published literature". Technological For Casting and Social Change 80:1331-1349.

[10]Kundi .M.K. and Hans_peterHutter,(2009). "Mobile Phone Base Stations Effects on Wellbeing and Health". Pathophysiology 16:123_135.

[11] Mousa ."Electromagnetic Radiation Mesurements and safety Issues of some cellular Base station in Nablus".Journal of Engineering Science and Technology Review 4 (1)(2011) 35-48.

[12] Poulletier de Gannes F,Billandel B,Haro E,Taxile M,Le MontagnerL, etal(2013)"Rat fertility and embryo fetal development in fluence of exposure to the Wi-Fi signal. Reprrod Toxical"36:1-5.

[13] Re Pacholi , Michel Repcholi, (2012). "Concer that (EMF) Magnetic Fields from Power Lines Cause Cancer". Science of total Environmental 426:454-458.

[14] Ronald Kitchen, (2001). "RF and Microwave Radiation Safety Hand book". Second Edition.

[15] S. Sivani, D Sudarsanam, (2012). "Impacts of RadioFrequency Electromagnetic Fields (RF_EMF) from Cell Phone Towers and Wireless devices on Bio system and Eco system ".

[16] UNDP, (1998), Unequal human impacts of environment damage, Human development report, 71.

[17] World resources institute, UNEP, UNDP, and World Bank, (1996). Urban environment, New York, Oxford University press, 24-25

\section{Author Profile}

Lorance Yahya Salih was born in Baghdad-Iraq in 1975. He was awarded a bachelor of Economic Sciences in 1997; afterward he was also awarded a Master of Economic Sciences in 2000. In 2006, he obtained his Ph.D in Economic Philosophy. He started his career as a lecturer in University of Baghdad, College of Administration and Economics 2005. 